has been exercised, The following points are reasonably clear: (1) that bacteria play a by no means unimportant rôle in bronchitic asthma ; (2) that no one bacterium is responsible-probably most of the catarrhal organisms play a part, but others cannot be excluded; (3) that considerable good can be done by mixed vaccines in some cases ; and (4) that accurate bacteriological and cytological observations upon a series of cases, correlating these with clinical observations, are much required to place the vaccine therapy of the condition upon a sound footing.

Harley-street, $W$.

\section{THE USE OF THE ULTRA-MICROSCOPE FOR THE EARLY DIAGNOSIS OF SYPHILIS.}

BY HUGH WANSEY BAYLY, M.A. CAMB., M.R.C.S. ENG., L.R.C.P. LOND.,

PATHOLOGIST TO THE LONDON LOCK HOSPITALS; ASSISTANT IN THE BACTERIOLOGICAL DEPARTMENT, ST. GEORGE'S HOSPITAL.

TrLL within the last year in Paris and at present in England most authorities have not considered the appearance of a primary chancre sufficiently diagnostic to justify the commencement of a three years' course of antisyphilitic treatment, and therefore have waited for the appearance of secondary symptoms before making a certain diagnosis and commencing the treatment. In this way error of diagnosis was obviated, but several weeks were lost during which the treponema pallidum was multiplying in the body, and the patient was subjected to the annoyance and discomfort of the secondary manifestations.

A diagnosis based on the staining of scrapings from the primary chancre or from a suspected sore-throat, with a view to demonstrate the presence of the treponema pallidum, was not very satisfactory, as this organism is difficult to stain and will be missed in a very considerable percentage of cases. The ultra-microscope, however, provides the means of making an early, rapid, and certain diagnosis and is now in routine use for this purpose in the Paris hospitals. Through the courtesy and kindness of Dr. Gastou, Chef de Laboratoire of the St. Louis Hospital, and Dr. Lacapère, Médecin de St. Lazare Hospital, I have been enabled to attend their cliniques and laboratory work recently and to appreciate the extreme value of the ultra-microscope as a means of diagnosis.

The ultra-microscope substitutes trans-, or rather oblique, illumination for direct illumination, and as the fine dust, invisible by direct illumination, appears as "motes in the sunbeam" by transillumination, so fine unstained particles with the ultra-microscope appear clear and distinct, and scrapings from primary or secondary lesions in the very great majority of untreated cases show the treponema pallidum. All lesions do not, however, show the treponema in equal numbers; thus the organism is present in the greatest numbers in mucous plaques, is usually present in only small numbers in chancres, and is very seldom found in the roseolar rash, though frequently found in some papular rashes. The organisms are found in the margin rather than in the centre of the lesions. The treponema has not been found in the blood by this method, except in some cases of congenital syphilis, neither has it been detected in tertiary lesions.

After a few weeks' treatment the number of the organisms is usually greatly reduced, and there may be considerable difficulty in finding one, but $I$ was told that out of a very large number of previously untreated chancres examined the treponema has been found in all but two, so that this method of diagnosis may be considered absolutely reliable for recent untreated sores. Even if untreated the treponemata tend to become fewer and slowly to disappear from the site of inoculation, so that absence of the treponema in a sore which has been present for over six weeks does not absolutely exclude syphilis, even if there has been no treatment. If a local antiseptic has been used the patient should be instructed to wash it away with plain water and return in three days.

Care must be taken not to confuse the treponema pallidum with the various other spirochætæ so frequently found in the mouth and genitalia. The treponema pallidum, however, is so characteristic in appearance and movements that an experienced observer is unlikely to mistake any other spirochæta for it.
The technique is very simple, the chief difficulty being the adjustment of the apparatus (light, condenser, mirror, and ultra-microscope). A small drop of distilled water or normal salt solution is first placed on the slide, and then the margin of the chancre, mucous plaque, or papule is gently scraped and the serum expressed by pressure, and a small quantity of this mixed with the drop of water on the slide. The distilled water causes the organism to swell when it can be more easily seen than in normal saline. A large cover-glass is now applied in the usual way and pressed down firmly, so that only a thin layer of fluid remains between the cover-glass and slide. A drop of immersion oil is now placed underneath the slide, which must be sufficient to fill the space between the lower surface of the slide and the upper surface of the ultra-microscope condenser, and a second drop is placed on the cover-glass in the usual way; the preparation is now ready for examination. The blood cells, bacteria, spirochætæ, \&c., will be seen as glistening refractive objects on a dark background.

Several makers (Zeiss, Leitz, and others) have ultra-microscopes on the market. I prefer the substage variety of Leitz, a diagram of which, showing the path of the light rays, is given below, as here the specimen can

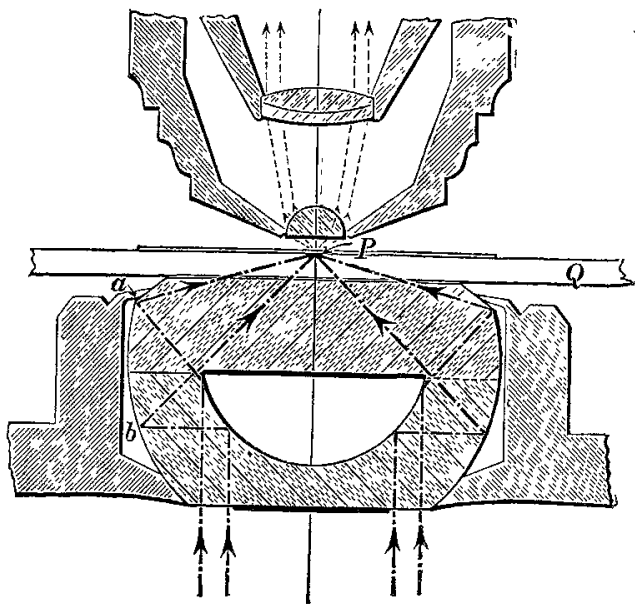

Diagram of the Leitz substage ultra-microscope. $a$ and $b$ show points of reflection of rays which pass through the slide $Q$ to converge on the point $P$.

be moved about with the microscope's usual mechanical stage; but the superstage variety has the advantage that it can be instantly removed when the microscope is required for ordinary microscopic work. Either variety of ultra-microscope can be fitted to any microscope at a trifling cost. A detailed account of the construction and use of the ultra-microscope will be found in a paper by Dr. Gastou and Dr. Comandon in the Bulletins et Mémoires de la Société Médioale des Hôpitaux de Paris of March 19th, 1909, entitled “ L'Ultra-Microscope et son Rôle Essentiel dans le Diagnostic de la Syphilis."

Brook-street, $W$

\section{Clinital Antes:}

MEDICAL, SURGICAL, OBSTETRICAL, AND THERAPEUTICAL.

\section{NOTHS ON THREE CASES OF MALARIA TREATED WITH INJECTIONS OF QUININE.}

BY GERALD W. YOUNG, M.D. EDIN., ACTING PRINCIPAL MEDICAL, OFFICER, RAILWAY HOSPITAL, ANTOFAGASTA, CHILE.

THE striking and immediate result which I obtained, albeit in only three cases, by the injection of a soluble salt of quinine in malaria has induced me to send the notes of the cases to THE LANCET. I do not remember where I read the method of treatment, but I made a note of it at the time when I was practising in South Africa and when I saw cases of malaria from time to time. The first case presented itself on board ship going from Oape Town to London; the second-a year later-at Uyuni in Bolivia; and the third has just left the hospital. I have never read any published aocounts of such treatment, and here have no literature on the subject to refer to. 